\title{
A large Indian family with rearrangement of chromosome 4p16 and 3p26.3 and divergent clinical presentations
}

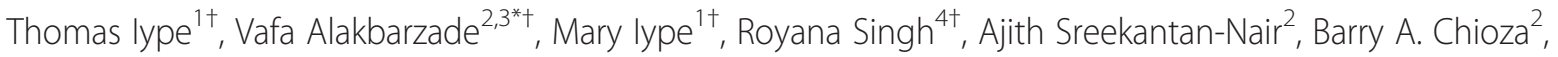
Tribhuvan M. Mohapatra ${ }^{4}$, Emma L. Baple ${ }^{2,7,8}$, Michael A. Patton ${ }^{2,6}$, Thomas T. Warner ${ }^{3}$, Christos Proukakis ${ }^{5}$, Abhi Kulkarni ${ }^{6}$ and Andrew H. Crosby ${ }^{2^{*}}$

\begin{abstract}
Background: The deletion of the chromosome 4p16.3 Wolf-Hirschhorn syndrome critical region (WHSCR-2) typically results in a characteristic facial appearance, varying intellectual disability, stereotypies and prenatal onset of growth retardation, while gains of the same chromosomal region result in a more variable degree of intellectual deficit and dysmorphism. Similarly the phenotype of individuals with terminal deletions of distal chromosome $3 p$ (3p deletion syndrome) varies from mild to severe intellectual deficit, micro- and trigonocephaly, and a distinct facial appearance.

Methods and results: We investigated a large Indian five-generation pedigree with ten affected family members in which chromosomal microarray and fluorescence in situ hybridization analyses disclosed a complex rearrangement involving chromosomal subregions 4p16.1 and 3p26.3 resulting in a 4p16.1 deletion and 3p26.3 microduplication in three individuals, and a 4p16.1 duplication and 3p26.3 microdeletion in seven individuals. A typical clinical presentation of WHS was observed in all three cases with 4p16.1 deletion and 3p26.3 microduplication. Individuals with a 4p16.1 duplication and 3p26.3 microdeletion demonstrated a range of clinical features including typical 3p microdeletion or $4 p$ partial trisomy syndrome to more severe neurodevelopmental delay with distinct dysmorphic features.
\end{abstract}

Conclusion: We present the largest pedigree with complex t(4p;3p) chromosomal rearrangements and diverse clinical outcomes including Wolf Hirschorn-, $3 p$ deletion-, and $4 p$ duplication syndrome amongst affected individuals.

Keywords: Wolf-Hirschhorn syndrome, WHS, Complex rearrangement of chromosome 4p16, 3p deletion syndrome, $4 p$ partial trisomy syndrome, Mental Retardation, Developmental delay

\section{Background}

Microscopically visible rearrangements of chromosome 4p16 may result in two separate syndromes: WolfHirschhorn syndrome (WHS) and partial trisomy $4 \mathrm{p}$ syndrome. WHS is a well-recognized contiguous gene deletion syndrome associated with prenatal and postnatal growth delay, a typical 'Greek warrior helmet' appearance of the nose, microcephaly, and neurological features including seizures, hypotonia and varying degrees of intellectual impairment [1]. In contrast, 4p16 duplication results in partial trisomy $4 \mathrm{p}$ syndrome, which gives

\footnotetext{
* Correspondence: v.alakbarzade@exeter.ac.uk; a.h.crosby@exeter.ac.uk †Equal contributors

${ }^{2}$ Molecular Genetics, RILD Institute, University of Exeter, Royal Devon and Exeter NHS Hospital, Wonford, Exeter, UK

Full list of author information is available at the end of the article
}

rise to variable clinical manifestations including intellectual disability, developmental delay and distinctive facial features [2-4].

About $40-45 \%$ of the WHS cases involve an unbalanced translocation and a deletion of $4 \mathrm{p}$ as well as partial trisomy of a different chromosome arm [5]. These unbalanced translocations may be de novo, or inherited from a parent with a balanced chromosomal rearrangement. Different rearrangements of chromosome $4 \mathrm{p}$ causing WHS and partial trisomy $4 \mathrm{p}$ syndrome in the same family have been reported $[2-4,6]$, as have a few reports of isolated unbalanced translocation involving chromosomes 4 and 3 [7-10]. The size of the chromosomal rearrangement and clinical presentations vary in these cases. Terminal and interstitial deletions of the short arm of chromosome 3 
comprises another contiguous gene deletion syndrome (3p deletion syndrome), which may also present with a variable clinical phenotype and associated with a number of different causal deletions. The core features of the syndrome typically include cognitive handicap, growth retardation, microcephaly, and facial dimorphism (ptosis, downslanting palpebral fissures and micrognathia), while variable features include congenital heart defects, postaxial polydactyly, cleft palate, renal and intestinal anomalies $[11,12]$. In this report, we document a large Indian pedigree in which individuals have inherited varying combinations of an unusual chromosomal translocation involving chromosome 4p16 and a small section of chromosome $3 \mathrm{p} 26.3$, resulting in a range of clinical phenotypes including Wolf-Hirschhorn syndrome, $4 \mathrm{p}$ partial trisomy- and 3p deletion syndrome.

\section{Methods and results}

\section{Study approval}

The present studies were reviewed and approved by the senior investigators from Banaras Hindu University, Varanasi, UP and Medical College, Trivandrum, Kerala and Royal Devon \& Exeter NHS Foundation Trust. All tissue samples were taken with informed consent in accordance with all ethical standards and protocols. The ethical clearance number is $\mathrm{EC} / 847$ and $\mathrm{EC}$ registration No. ECR/526/INSt/UP2014. All subjects or their guardians provided informed consent prior to their participation in the study and for publishing this research article. Written parental consent also was obtained to publish any images of minors. Written informed consent was obtained to publish the photographs of affected individuals.

\section{Clinical report}

The family, from Kerala (South India), comprises a total of 36 members over five generations (Fig. 1). All 10 affected subjects were evaluated by a neurologist and a clinical geneticist. Pregnancy and delivery of 9/10 affected individuals was uncomplicated, with delivery at gestational age 38 weeks while IV:11 was born pre-term. Patient clinical data and findings are summarized in Tables 1 and 2.

$\mathrm{V}: 1$ (born in 2000) and V:2 (born in 2004) are the only affected siblings in generation $\mathrm{V}$ of the pedigree. Birth weight was $1.5 \mathrm{~kg}$ in both cases, length and head circumference at birth were not reported. V:1 was floppy at birth, and developed severe physical and psychomotor developmental delay (sitting at 4 years, currently can only stand with support, delayed or poor eye contact and no speech). A past history of febrile seizures and status epilepticus is reported. Stereotypies of recent onset included

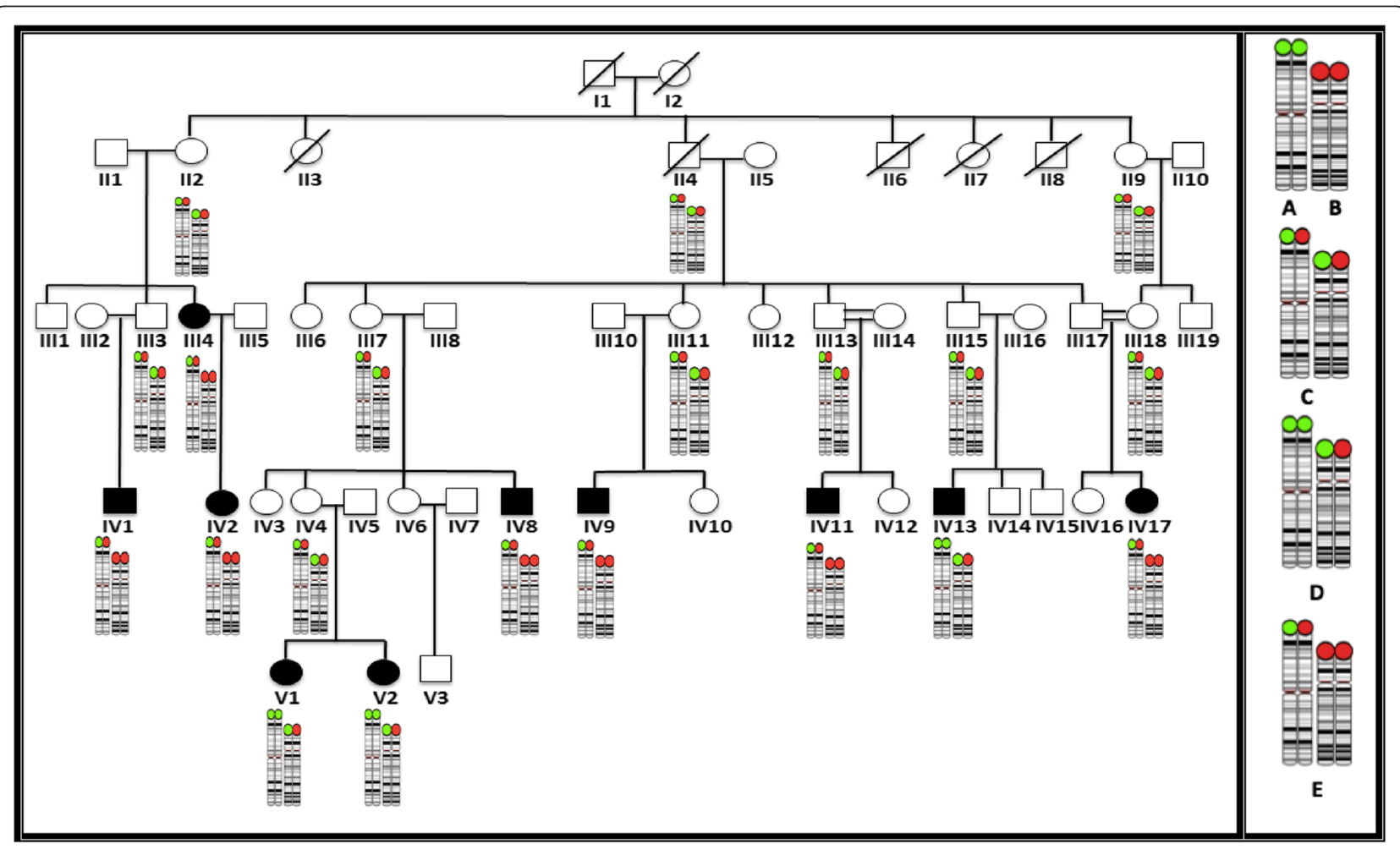

Fig. 1 Left panel: family pedigree including an illustration of the chromosome 3 and 4 al rearrangement detected. Right panel: normal chromosome 3 telomere, demarcated with green circle (a) and normal chromosome 4 telomere, with red circle (b). A balanced translocation outcome is shown in $\mathbf{c}$, while unbalanced translocation outcomes are shown in $\mathbf{d}$ ( $3 p$ duplication and $4 p$ deletion) and e (3p deletion, $4 p$ duplication) 
Table 1 Clinical presentation of the three patients with the chromosomes 4p16 deletion and 3p26.3 duplication

\begin{tabular}{|c|c|c|c|}
\hline & $\mathrm{V}: 1$ & $\mathrm{~V}: 2$ & IV:13 \\
\hline$\overline{\text { Age }}$ & 12.5 & 8.8 & 12 \\
\hline Gender & $\mathrm{F}$ & $\mathrm{F}$ & M \\
\hline \multicolumn{4}{|l|}{ Growth Parameters } \\
\hline Height $\left(\mathrm{cm} / \mathrm{SDS}^{\mathrm{a}}\right)$ & $109 /-5.9$ & $110 /-5.3$ & $128 /-0.3$ \\
\hline Head circumference $\left(\mathrm{cm} / \mathrm{SDS}^{\mathrm{a}}\right)$ & $43 /-8.8$ & $42 /-8.0$ & $48 /-4.2$ \\
\hline Severe mental retardation & + & + & + \\
\hline \multicolumn{4}{|l|}{ Facial features of WHS:: } \\
\hline - High arched eyebrows & + & + & + \\
\hline - Broad flat nasal bridge & + & + & + \\
\hline - Prominent nasal tip & + & + & + \\
\hline - Prominent eyes & + & + & + \\
\hline - Ocular hypertelorism & + & + & + \\
\hline - Short philtrum & + & + & + \\
\hline - Downturned mouth & + & + & + \\
\hline - Micrognathia & + & + & + \\
\hline Seizures & - & + & + \\
\hline Prenatal growth delay & + & + & + \\
\hline Hypotonia & + & + & + \\
\hline
\end{tabular}

${ }^{a} S D S$ standard deviation score (http://www.who.int/childgrowth/standards/en/); above ( -2 SDS) normal average

rocking and repeated hand washing. Dysmorphic facial features were noted (Table 1; Additional file 1: Figure S1) as well as hand malformations including tapering-long fingers, bilateral inability to abduct the thumb, single transverse palmar crease, hypermobile metacarpophalangeal joints of thumb, overlapping fingers and pes planus. Neurological examination at 12 years of age revealed: increased tone and reflexes in lower limbs. At the age of 12 she developed stereotypic body movements such as bending from side to side, body rocking and hand washing. The younger sibling $(\mathrm{V}: 2)$ required ventilation for a month post-delivery. Developmental milestones were delayed, walked with support at age 2 . Speech is limited to a few words and she is unable to read and write. Generalised tonic-clonic seizures developed at 17 months. Unilateral agenesis of the kidney was seen on ultrasound. Additional clinical features included sacral dimple, overlapping and tapered fingers, flexion contracture of proximal interphalangeal joints, inability to abduct the thumb, simian hand line, hypermobile metocarpophalangeal joint of thumb, rocker bottom feet, prominent talus, medial malleolus, ear deformities (left preauricular sinus, small ears with small lobule, 'cauliflower' shaped left ear and pointed pinna). Neurological examination conducted at age 8 revealed left lower motor neuron facial palsy, reduced tone (upper limbs), and increased tone in the lower extremities with exaggerated reflexes. MRI imaging of the brain showed hypo-dense lesions in frontal lobes.

IV:13 is a maternal cousin of siblings $V: 1$ and $V: 2$. His birth weight was $1.8 \mathrm{~kg}$. Developmental concerns were noted early on and progress was similar to $\mathrm{V}: 1$. At the age of 2 he had not developed speech and walking, could sit with support and independently roll from back to front. He developed epilepsy with generalized tonic-clonic seizures at 12 months, which is currently under control on phenytoin. He also has swallowing difficulties, drooling and urinary incontinence. He responds to noise, and recognizes his parents. Behavioral problems include selfharm and stereotypies including body rocking movements. Facial features are as described in Table 1 and ear and limb deformities resembling those of $\mathrm{V}: 2$. Additional findings included: strabismus, a high arched palate, cleft lip, fixed flexion deformity of the elbows, flat occiput and widely spaced nipples. Neurological examination revealed generalized hypotonia, brisk reflexes and out-turned feet. Ultrasonography revealed kidney malformation, and brain MRI revealed dysgenesis of the corpus callosum.

Individual IV:11 was born pre-term (birth weight $1.2 \mathrm{~kg}$ ) to consanguineous parents. He had severe developmental delay with no speech and walked with support at age 3 . He responds to sounds but hearing function has not been tested. He has a history of surgically treated cleft lip and complex partial seizures. On neurological examination he had gaze evoked nystagmus, limb ataxia, gait ataxia; exaggerated knee and ankle jerks and up-going plantar reflexes. The dysmorphic features are described in Table 2 and Additional file 1: Figure S1. Additional findings on examination were sacral dimple, strabismus and hypospadius. Behavioral abnormalities included stereotypies including rocking, hand wringing, repeated hand washing, head banging and self-harm.

III:4 was the eldest affected child of the third generation. She had no speech or walk until age 2 and has medically resistant secondarily generalized tonic-clonic seizures. At the time of assessment she could not walk unaided, her speech was dysarthric with limited vocabulary and she was unable to read or write. Neurological examination revealed kyphosis, reduced upper limb deep tendon reflexes, absent knee and ankle jerk, hypotonia, scanning speech, gaze evoked nystagmus, and an ataxic gait. Facial features were as described in Table 2. Her daughter, IV:2, started to walk at age 3 and speak at age 4 . She displayed aggressive behavior and had mild intellectual impairment. Neurological examination revealed absent knee and ankle jerks and dysarthria. No history of seizures was reported, and distinctive dysmorphic features were noted (Table 2).

IV:17 was born to consanguineous parents. Apart from mild learning difficulties and limited vocabulary, no neurological or other physical abnormalities were detected on examination. 
Table 2 Clinical presentation of the seven patients with chromosomes 4p16.1 duplication and 3p26.3 microdeletion

\begin{tabular}{|c|c|c|c|c|c|c|c|}
\hline Case & III:4 & $\mathrm{IV}: 8$ & $\mathrm{IV}: 9$ & $\mathrm{IV}: 2$ & $\mathrm{IV}: 11$ & $\mathrm{IV}: 1$ & IV:17 \\
\hline Age & 40 & 20.5 & 16.7 & 16.1 & 14.1 & 11.7 & 7.9 \\
\hline Sex & $\mathrm{F}$ & M & M & $\mathrm{F}$ & M & M & $\mathrm{F}$ \\
\hline Developmental delay & + & + & + & - & + & + & + \\
\hline Intellectual disability & Severe & Mild & Mild & Mild & Severe & Mild & Mild \\
\hline Height (cm/SDS) & $157 /-1.1$ & $179 / 0.2$ & $172 /-0.4$ & $151 /-2.0$ & $130 /-3.8$ & $143 /-0.3$ & $122 /-0.4$ \\
\hline $\begin{array}{l}\text { Head circumference } \\
\text { (cm/SDS) }\end{array}$ & $52 /-2.5$ & 55/-1.3/Mild & $53.5 /-1.9 /$ & $53 /-1.7$ & $49 /-4.1 /$ & $51 /-2.4 /$ & $51 /-1.5$ \\
\hline Shape & NAD & Brachycephaly & Brachycephaly & NAD & Trigonocephaly & Brachycephaly & NAD \\
\hline \multirow[t]{3}{*}{ Facial features } & \multirow[t]{3}{*}{$\begin{array}{l}\text { Prominent supraorbital } \\
\text { ridges \& glabella; prominent } \\
\text { midface; prognathism }\end{array}$} & \multirow[t]{3}{*}{$\begin{array}{l}\text { Mild prominence } \\
\text { supraorbital ridges \& } \\
\text { glabella }\end{array}$} & \multirow[t]{3}{*}{$\begin{array}{l}\text { Prominent supraorbital } \\
\text { ridges \& glabella; prominent } \\
\text { midface; mild prognathism }\end{array}$} & \multirow[t]{3}{*}{$\begin{array}{l}\text { Mild prominence of supraorbital } \\
\text { ridges \& glabella; prominent } \\
\text { midface; prognathism }\end{array}$} & $\begin{array}{l}\text { Hypertelorism, Prominent } \\
\text { midface; Flat broad nasal } \\
\text { tip, low hanging columella }\end{array}$ & \multirow[t]{3}{*}{ NAD } & \multirow[t]{3}{*}{ NAD } \\
\hline & & & & & Highly arched eyebrows & & \\
\hline & & & & & $\begin{array}{l}\text { Low frontal and nuchal } \\
\text { hair line }\end{array}$ & & \\
\hline \multirow[t]{2}{*}{ Nose } & \multirow[t]{2}{*}{ Prominent nasal tip } & \multirow[t]{2}{*}{ Prominent nasal tip } & \multirow[t]{2}{*}{ Prominent nasal tip } & \multirow[t]{2}{*}{ Prominent nasal tip } & Broad high nasal bridge & \multirow{2}{*}{$\begin{array}{l}\text { Flat nasal } \\
\text { bridge }\end{array}$} & \multirow[t]{2}{*}{ NAD } \\
\hline & & & & & Prominent nasal tip & & \\
\hline \multirow[t]{2}{*}{ Mouth } & \multirow{2}{*}{$\begin{array}{l}\text { Thin vermillion of the } \\
\text { upper lip; High arched } \\
\text { palate; cleft lip; gum } \\
\text { hypertrophy }\end{array}$} & \multirow[t]{2}{*}{$N A D^{a}$} & \multirow[t]{2}{*}{ High arched palate } & \multirow[t]{2}{*}{ NAD } & Short philtrum & \multirow[t]{2}{*}{ NAD } & \multirow[t]{2}{*}{ NAD } \\
\hline & & & & & Cleft lip & & \\
\hline Ears & Strabismus & Low set ears & $\begin{array}{l}\text { Prominent ears, malformed } \\
\text { helix }\end{array}$ & Prominent, low set ears & $\begin{array}{l}\text { Low set ears; malformed } \\
\text { helix }\end{array}$ & Low set ears & NAD \\
\hline Hand deformity & Campodactyly & \multirow[t]{2}{*}{ Campodactyly } & \multirow[t]{2}{*}{ Long digits } & \multirow[t]{2}{*}{ NAD } & \multirow[t]{2}{*}{ Campodactyly } & \multirow[t]{2}{*}{ Clindactily } & \multirow[t]{2}{*}{ NAD } \\
\hline Feet deformity & $\begin{array}{l}\text { Pes cavus; inversion deformity } \\
\text { of feet }\end{array}$ & & & & & & \\
\hline Seizures & + & $-\mathrm{b}$ & - & - & + & - & - \\
\hline
\end{tabular}

${ }^{a}$ NAD- no abnormality detected; ${ }^{b}$ - no seizures 
IV:8, IV:9 and IV:1 had delayed walking and speech at $2.5-3$ years, and similar levels of mild learning difficulties. The birth weight of only IV:8 was documented $(2.5 \mathrm{~kg})$. Individual IV:8 could never run due to poor balance, and although he went to a school up to tenth grade, his intellectual abilities are limited. On neurological examination had mild upper and lower motor neuron signs, ataxia and could not stand on his heels. Brain MRI revealed mild cerebral atrophy. Case IV:9 had a previous history of lumbar discectomy. All the observed phenotypic abnormalities are described in Table 2 and Additional file 1: Figure S1.

\section{Microarray analysis and flourescent in situ hybridization (FISH)}

DNA samples from family members were genotyped using the Illumina HumanCytoSNP-12 v2.1 microarrays to detect copy-number variations (CNVs). The Illumina Infinium HD assay protocol was followed and the array processed on a BeadStation 500G. Image data was processed in the Illumina GenomeStudio software to generate genotype calls, B allele frequency and $\log \mathrm{R}$ ratio values. These were further analysed for CNVs using Illumina's KaryoStudio software. This revealed a 3p26.3 (0-2144867)x3duplication and 4p16.3-16.1 (0-10308871)x1 deletion in three affected individuals (IV:13; V:1; V:2), and a reciprocal 3p26.3 (02118422)x1deletion and 4p16.3-16.1 (0-10290552)x3duplication in seven affected individuals (III:4; IV:8; IV:9; IV:2; IV:11; IV:1; IV:17), including two (III:4 and IV:11) with more severe phenotype than others (Additional file 1: Table S1, Figure S1 and Figure S2). For FISH, Kreatech probes D4S33060 and D3S4558 were used to define either balanced or unbalanced $\mathrm{t}(3 \mathrm{p} ; 4 \mathrm{p})$ translocations in three individuals, case V:2, IV:9 and III:3 on whom samples were available for study (Additional file 1: Figure S3).

\section{Discussion and conclusions}

We describe a complex reciprocal translocation involving chromosomes 3 and 4 in ten affected family members of a five-generation pedigree, resulting in clinical manifestations of 3 rare chromosomal syndromes. This is, to our knowledge, the first reported case study of a chromosomal imbalance that combines chromosome $4 p$ deletion (WHS), $4 \mathrm{p}$ partial trisomy and $3 \mathrm{p}$ deletion syndromes in the same family. Nine of the 10 affected family members (II:2; III:7; III:10; III:12; III:14; III:17 and IV:4) were born from a healthy parent with a balanced translocation of chromosomes 3 and 4, while a single affected individual (IV:2) inherited her imbalanced chromosomal complement from her affected mother (III:4) who herself displayed the same 4p16.1 duplication and 3p.26.3 microdeletion.

Deletion of the chromosome $4 \mathrm{p}$ region has previously been shown to result in a widely recognized phenotype compared with gains of the same region, which result in more variable clinical manifestations. The family described here includes three family members with chromosome $4 \mathrm{p}$ deletion resulting in WHS, all of whom displayed the typical clinical features of this condition. The characteristic phenotype of WHS includes a typical facial appearance, significant intellectual disability and poor growth [13]. The high arched eyebrows and prominent nasal tip that were seen in all three WHS cases described here may relate to the progression of these facial features with age, as has been previously suggested [1]. Similarly, the ear hand and feet anomalies, and dysgenesis of corpus callosum, have previously been documented in WHS cases $[1,14]$.

At a molecular level, within the terminal $1.9 \mathrm{Mb}$ region on 4p16.3, Wolf-Hirschhorn syndrome candidate region 2 (WHSCR-2) was described as the likely critical region for WHS [15]. Candidate genes in that region have been suggested to cause particular clinical aspects of WHS $[16,17]$. Haploinsufficiency of the WHSC1 gene [OMIM 602952], which is disrupted by the proximal breakpoint of WHSCR2 , has been associated with both facial characteristics and growth delay $[18,19]$. The LETM1 gene, residing entirely within WHSCR-2, is considered to play an important role in the pathogenesis of seizures [20-24]. However, genotype-phenotype correlation analyses suggested that haploinsufficiency of LETM1 alone may not be sufficient in causing seizures and that loss of the terminal $1.5 \mathrm{Mb}$ region with breakpoint at $\sim 300 \mathrm{~kb}$ from the LETM1 locus, preserving LETM1, is critical for the development of a seizure disorder [25]. Large deletions of chromosome 4 p16 incorporating both critical regions are typically associated with profound intellectual disability, seizures and psychosis in addition to the typical facial appearance $[15,18,19]$. Our microarray analysis of the three WHS cases described here with 4p16.3-16.1 deletion and 3p26.3 duplication identified a $\sim 5 \mathrm{Mb}$ deletion encompassing WHSCR-2 which resulted in severe developmental delay with absent $(2 / 3)$ or impaired speech $(1 / 3)$, absent $(2 / 3)$ or significantly delayed onset of walking $(1 / 3)$, as well as generalized tonic-clonic seizures $(3 / 3)$ and behavioral abnormalities (2/3), consistent with those previously described in WHS.

Compared to the classical presentation seen in the three WHS patients, the seven chromosome 4p partial trisomy patients displayed a much more variable clinical picture. The degree of intellectual deficit present across the seven cases varied from severe $(2 / 7)$ to mild (4/7). The majority of the seven patients displayed clinical features previously described for trisomy of $4 \mathrm{p}$ syndrome, including prominent supraorbital ridges (5/7), prominent nasal tip (5/7), prognathism (3/7), camptodactyly (2/ 7) and malformed and low-set ears (5/7). Although head circumference was reduced in all seven cases, height was variable ranging from normal $(5 / 7)$ to short stature $(2 / 7)$ 
(Table 2). Overexpression or inactivating mutations of two genes mapping to the chromosomal region involved, fibroblast growth factor receptor 3 (FGFR3) and WHSC1, have been reported to be associated with overgrowth features such as macrocephaly, campodactyly and tall stature $[26,27]$. FGFR3 is a physiological negative regulator of bone growth, and has been associated with syndromic presentations affecting bone growth including the overgrowth syndrome-CATSHL (campodactyly, tall stature, and hearing loss) [26]. Similarly, overexpression of WHSC1 has been suggested as a contributor to the overgrowth seen as part of this condition. In mice, haploinsufficency of WHSC1 resulted in growth retardation [27]. Two of the 7 chromosome $4 \mathrm{p}$ duplication cases (III:4 and IV:11) demonstrated discordant clinical manifestations including severe intellectual disability, short stature, microcephaly, generalized tonic-clonic seizures, gum hypertrophy and cerebellar signs, compared with relatively mild learning difficulties in the remaining five cases (IV:8; IV:9; IV:2; IV:1 and IV:17). The cerebellar signs and gum hypertrophy seen in the 2 severely affected cases may relate to long term phenytoin treatment.

The craniofacial features observed in 1 of the 2 partial 4p trisomy cases (IV:11), including high arched eye brows, hypertelorism, trigonocephaly as well as marked reduction in growth milestones and behavioral changes, are not previously recognized in partial $4 \mathrm{p}$ trisomy syndrome (Table 2; \& Additional file 1: Figure S1). While this may reflect as-yet unrecognized clinical variability in this disorder, it is more likely to be due to the complexity of the chromosome imbalance in these cases.

The chromosome 3pter rearrangement defined here is somewhat smaller compared with rearrangements previously reported as part of chromosome $3 p$ duplication syndrome. The $2.7 \mathrm{Mb}$ chromosome 3 microdeletion detected in this family includes the CNTN4 and CHL1 genes, which have previously been shown to have a pleotropic effect and contribute to learning difficulties in affected individuals [28-33]. Further, CNTN4 deletion has been associated with microcephaly, trigonocephaly, hypertelorism, growth retardation and ear abnormalities. However these clinical features were present in only two of the seven chromosome 3p26.3 microdeletion cases (III:4 \& IV:11) presented here. This may mean that other factors including age of examination, other genes in the 3pter region, epigenetic phenomena, expression or regulatory variation and the unmasking of recessive variants residing on the other unperturbed allele, may also be required for the development of these features.

\section{Availability of supporting data}

All the supporting data are included as Additional file 1 and available in the online version of the paper.

\section{Additional file}

Additional file 1: Supplemental information includes a table that illustrates DNA copy alterations identified using micro-array copy number analysis, the photos of affected individuals, the illustration of beadarray analysis of SNP data, used to identify the chromosomal subregion duplication and deletion events present in family members, and FISH karyotype analyses. (DOCX 1037 kb)

\section{Abbreviations}

WHS: Wolf-Hirschhorn syndrome; CNVs: Copy-number variations;

WHSCR: Wolf-Hirschhorn syndrome critical regions; CATSHL: Campodactyly, tall stature, and hearing loss; FGFR3: Fibroblast growth factor receptor 3; LETM1: Leucine zipper/EF-hand-containing transmembrane protein 1.

\section{Competing interests}

The authors declare that they have no competing interests.

\section{Authors' contributions}

AHC and TI conceived, designed and supervised the project. VA, AS-H, AK and $\mathrm{BAC}$ performed experiments. $\mathrm{TI}$ and $\mathrm{MI}$ aided in family recruitment. TI, VA, CP, ELB, RS, MAP, TMM and TTW aided in assessment of clinical data. VA and $\mathrm{AHC}$ wrote the manuscript. All authors read and approved the final version of the manuscript.

\section{Acknowledgement}

The work was supported by UK Medical Research Council grants G1002279 and G1001931 and by the Newlife Foundation for disabled children.

\section{Author details}

'Department of Neurology, Government Medical College, Thiruvananthapuram, Kerala, India. ${ }^{2}$ Molecular Genetics, RILD Institute, University of Exeter, Royal Devon and Exeter NHS Hospital, Wonford, Exeter, UK. ${ }^{3}$ Reta Lila Weston Institute of Neurological Studies, UCL Institute of Neurology, London, UK. ${ }^{4}$ Department of Anatomy and Microbiology, Institute of Medical Sciences, Banaras Hindu University, Varanasi, Uttar Pradesh, India. ${ }^{5}$ Clinical Neuroscience, Royal Free Campus, UCL Institute of Neurology, London, UK. 'Southwest Thames Regional Genetics Centre, St George's Healthcare NHS Trust, London SW17 ORE, UK. ${ }^{7}$ Human Genetics and Genomic Medicine, Faculty of Medicine, University of Southampton, Southampton, UK. ${ }^{8}$ Wessex Clinical Genetics Service, Princess Anne Hospital, Southampton, UK.

Received: 10 July 2015 Accepted: 4 November 2015

Published online: 10 November 2015

\section{References}

1. Battaglia A, Carey JC, Viskochil DH, Cederholm P, Opitz JM. Wolf-Hirschhorn syndrome (WHS): a history in pictures. Clin Dysmorphol. 2000;9(1):25-30.

2. Patel SV, Dagnew H, Parekh AJ, Koenig E, Conte RA, Macera MJ, et al. Clinical manifestations of trisomy $4 p$ syndrome. Eur J Pediatr. 1995;154(6):425-31.

3. Partington MW, Fagan K, Soubjaki V, Turner G. Translocations involving 4 p16.3 in three families: deletion causing the Pitt-Rogers-Danks syndrome and duplication resulting in a new overgrowth syndrome. J Med Genet. 1997;34(9):719-28.

4. Schonewolf-Greulich B, Ravn K, Hamborg-Petersen B, Brondum-Nielsen K, Tumer Z. Segregation of a 4p16.3 duplication with a characteristic appearance, macrocephaly, speech delay and mild intellectual disability in a 3-generation family. Am J Med Genet A. 2013;161(9):2358-62.

5. Battaglia A, Carey JC, Wright TJ. Wolf-Hirschhorn (4p-) syndrome. Adv Pediatr. 2001;48:75-113.

6. Gonzalez CH, Sommer A, Meisner LF, Elejalde BR, Opitz JM. The trisomy 4p syndrome: case report and review. Am J Med Genet. 1977;1(2):137-56.

7. Schinzel A, Hanson JW, Pagon RA, Hoehn H, Smith DW. Trisomy 3 (p23-pter) resulting from maternal translocation, t $(3 ; 4)(\mathrm{p} 23 ; \mathrm{q} 35)$. Ann Genet. 1978;21(3):168-71.

8. Petriczko E, Biczysko-Mokosa A, Bogdanowicz J, Constantinou M, Zdziennicka E, Horodnicka-Jozwa A, et al. Familial distal monosomy 3p26.3-pter with trisomy 4q32.2-qter, presenting with progressive ataxia, intellectual disability, and dysmorphic features. Am J Med Genet A. 2012;158a(6):1442-6. 
9. Grossmann V, Muller D, Muller W, Fresser F, Erdel M, Janecke AR, et al. "Essentially" pure trisomy 3q27 -> qter: further delineation of the partial trisomy 3q phenotype. Am J Med Genet A. 2009;149a(11):2522-6.

10. Han DH, Chang JY, Lee Wl, Bae CW. A case of partial trisomy 3p syndrome with rare clinical manifestations. Korean J Pediatr. 2012;55(3):107-10.

11. Cargile CB, Goh DL, Goodman BK, Chen XN, Korenberg JR, Semenza GL, et al. Molecular cytogenetic characterization of a subtle interstitial del(3)(p25.3p26.2) in a patient with deletion 3p syndrome. Am J Med Genet. 2002;109(2):133-8.

12. Malmgren $H$, Sahlen S, Wide K, Lundvall M, Blennow E. Distal 3p deletion syndrome: detailed molecular cytogenetic and clinical characterization of three small distal deletions and review. Am J Med Genet A. 2007;143a(18):2143-9.

13. Zollino M, Murdolo M, Marangi G, Pecile V, Galasso C, Mazzanti L, et al. On the nosology and pathogenesis of Wolf-Hirschhorn syndrome: genotype-phenotype correlation analysis of 80 patients and literature review. Am J Med Genet C: Semin Med Genet. 2008;148C(4):257-69.

14. Verbrugge J, Choudhary AK, Ladda R. Tethered cord, corpus callosum abnormalities, and periventricular cysts in Wolf-Hirschhorn syndrome. Report of two cases and review of the literature. Am J Med Genet A. 2009;149A(10):2280-4.

15. Zollino M, Lecce R, Fischetto R, Murdolo M, Faravelli F, Selicorni A, et al. Mapping the Wolf-Hirschhorn syndrome phenotype outside the currently accepted WHS critical region and defining a new critical region, WHSCR-2. Am J Hum Genet. 2003;72(3):590-7.

16. Stec I, Wright TJ, van Ommen GJ, de Boer PA, van Haeringen A, Moorman AF, et al. WHSC1, a 90 kb SET domain-containing gene, expressed in early development and homologous to a Drosophila dysmorphy gene maps in the Wolf-Hirschhorn syndrome critical region and is fused to $\operatorname{lgH}$ in $\mathrm{t}(4 ; 14)$ multiple myeloma. Hum Mol Genet. 1998;7(7):1071-82.

17. Wright TJ, Costa JL, Naranjo C, Francis-West P, Altherr MR. Comparative analysis of a novel gene from the Wolf-Hirschhorn/Pitt-Rogers-Danks syndrome critical region. Genomics. 1999;59(2):203-12.

18. Wright TJ, Ricke DO, Denison K, Abmayr S, Cotter PD, Hirschhorn K, et al. A transcript map of the newly defined $165 \mathrm{~kb}$ Wolf-Hirschhorn syndrome critical region. Hum Mol Genet. 1997:6(2):317-24

19. Rodriguez L, Zollino M, Climent S, Mansilla E, Lopez-Grondona F, Martinez-Fernandez ML, et al. The new Wolf-Hirschhorn syndrome critical region (WHSCR-2): a description of a second case. Am J Med Genet A. 2005;136(2):175-8

20. Nowikovsky K, Froschauer EM, Zsurka G, Samaj J, Reipert S, Kolisek M, et al. The LETM1/YOL027 gene family encodes a factor of the mitochondrial K+ homeostasis with a potential role in the Wolf-Hirschhorn syndrome. J Biol Chem. 2004;279(29):30307-15.

21. Schlickum S, Moghekar A, Simpson JC, Steglich C, O'Brien RJ, Winterpacht A, et al. LETM1, a gene deleted in Wolf-Hirschhorn syndrome, encodes an evolutionarily conserved mitochondrial protein. Genomics. 2004;83(2):254-61.

22. Frazier AE, Taylor RD, Mick DU, Warscheid B, Stoepel N, Meyer HE, et al. Mdm38 interacts with ribosomes and is a component of the mitochondrial protein export machinery. J Cell Biol. 2006;172(4):553-64.

23. Jiang D, Zhao L, Clapham DE. Genome-wide RNAi screen identifies Letm1 as a mitochondrial Ca2+/H+ antiporter. Science. 2009;326(5949):144-7.

24. DiMauro S, Kulikova R, Tanji K, Bonilla E, Hirano M. Mitochondrial genes for generalized epilepsies. Adv Neurol. 1999;79:411-9.

25. Zollino M, Orteschi D, Ruiter M, Pfundt R, Steindl K, Cafiero C, et al. Unusual 4 p16.3 deletions suggest an additional chromosome region for the WolfHirschhorn syndrome-associated seizures disorder. Epilepsia. 2014;55(6):849-57.

26. Toydemir RM, Brassington AE, Bayrak-Toydemir P, Krakowiak PA, Jorde LB, Whitby FG, et al. A novel mutation in FGFR3 causes camptodactyly, tall stature, and hearing loss (CATSHL) syndrome. Am J Hum Genet. 2006;79(5):935-41.

27. Nimura K, Ura K, Shiratori H, Ikawa M, Okabe M, Schwartz RJ, et al. A histone H3 lysine 36 trimethyltransferase links Nkx2-5 to Wolf-Hirschhorn syndrome. Nature. 2009;460(7252):287-91.

28. Dijkhuizen T, van Essen T, van der Vlies P, Verheij JB, Sikkema-Raddatz B, van der Veen AY, et al. FISH and array-CGH analysis of a complex chromosome 3 aberration suggests that loss of CNTN4 and CRBN contributes to mental retardation in 3pter deletions. Am J Med Genet A. 2006;140(22):2482-7.

29. Conte RA, Pitter JH, Verma RS. Molecular characterization of trisomic segment 3p24.1-> 3pter: a case with review of the literature. Clin Genet. 1995;48(1):49-53.
30. Kotzot D, Kruger C, Braun-Quentin C. De novo direct duplication 3 (p25-> pter): a previously undescribed chromosomal aberration. Clin Genet. 1996;50(2):96-8.

31. Pohjola P, de Leeuw N, Penttinen M, Kaariainen $\mathrm{H}$. Terminal $3 p$ deletions in two families-correlation between molecular karyotype and phenotype. Am J Med Genet A. 2010;152A(2):441-6.

32. Frints SG, Marynen P, Hartmann D, Fryns JP, Steyaert J, Schachner M, et al. CALL interrupted in a patient with non-specific mental retardation: gene dosage-dependent alteration of murine brain development and behavior. Hum Mol Genet. 2003;12(13):1463-74.

33. Shrimpton AE, Jensen KA, Hoo JJ. Karyotype-phenotype analysis and molecular delineation of a 3p26 deletion/8q24.3 duplication case with a virtually normal phenotype and mild cognitive deficit. Am J Med Genet A. 2006;140(4):388-91.

\section{Submit your next manuscript to BioMed Central and take full advantage of:}

- Convenient online submission

- Thorough peer review

- No space constraints or color figure charges

- Immediate publication on acceptance

- Inclusion in PubMed, CAS, Scopus and Google Scholar

- Research which is freely available for redistribution 